\title{
KRAS NP_004976.2:p.A59X
}

National Cancer Institute

\section{Source}

National Cancer Institute. KRAS NP 004976.2:p.A59X. NCI Thesaurus. Code C147575.

A change in the amino acid residue at position 59 in the GTPase KRas protein where alanine has been replaced by another amino acid. 